\title{
Purification and characterization of GAD65-specific
}

\section{monoclonal autoantibodies [version 1; peer review: 1}

\section{approved, 1 approved with reservations]}

\author{
Wei Jiang 1,2, Henriette Macmillan¹-3, Anne-Marie Madec ${ }^{4}$, Elizabeth D. Mellins (Did,2 \\ ${ }^{1}$ Department of Pediatrics, Stanford University, Stanford, CA, 94305, USA \\ 2Stanford Program in Immunology, Stanford University, Stanford, CA, 94305, USA \\ ${ }^{3}$ Department of Medicine, University of California San Francisco, San Francisco, CA, 94143, USA \\ 4INSERM U1060, Faculté de médecine Lyon-Sud, Oullins Cedex, France
}

V1 First published: 29 May 2015, 4:135

https://doi.org/10.12688/f1000research.6467.1

Latest published: 21 Apr 2016, 4:135

https://doi.org/10.12688/f1000research.6467.2

\section{Abstract}

Autoantibodies against antigens expressed by insulin-producing $\beta$ cells are circulating in both healthy individuals and patients at risk of developing Type 1 diabetes. Recent studies suggest that another set of antibodies (anti-idiotypic antibodies) exists in this antibody/antigen interacting network to regulate auto-reactive responses. Anti-idiotypic antibodies may block the antigen-binding site of autoantibodies or inhibit autoantibody expression and secretion. The equilibrium between autoantibodies and anti-idiotypic antibodies plays a critical role in mediating or preventing autoimmunity. Herein, using GAD65/anti-GAD65 autoantibodies as a model system, we aimed at establishing reliable approaches for purification of highly pure autoantibodies for the downstream investigation of molecular mechanisms underlying such a network.

\section{Keywords}

GAD65-specific, monoclonal autoantibody, affinity purification, autoantibody production

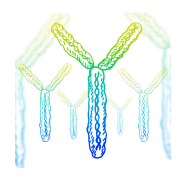

This article is included in the Antibody

Validations gateway.

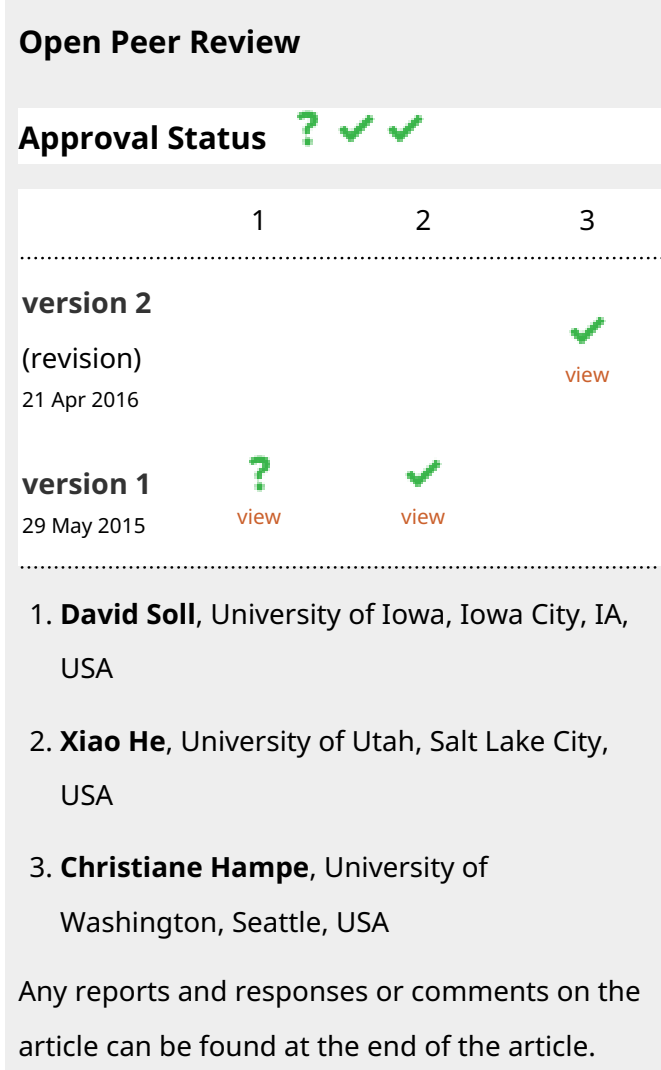


Corresponding authors: Wei Jiang (wjiang6@stanford.edu), Elizabeth D. Mellins (mellins@stanford.edu)

Competing interests: No competing interests were disclosed.

Grant information: This work was supported by National Institutes of Health Grants AI095813 and AI075253 (both to E.D.M.), the Stanford NIH/NCRR CTSA award UL1 RR025744 (to W.J.), National Institutes of Health/National Center for Research Resources Clinical and Translational Science Award UL1 RR025744 (to H.M.), and the Lucile Packard Foundation for Children's Health. H.M. was also supported by National Institutes of Health Training Grant T32 AI07290 to the Stanford Interdisciplinary Program in Immunology. The funders had no role in study design, data collection and analysis, decision to publish, or preparation of the manuscript.

Copyright: $\odot 2015$ Jiang W et al. This is an open access article distributed under the terms of the Creative Commons Attribution License, which permits unrestricted use, distribution, and reproduction in any medium, provided the original work is properly cited.

How to cite this article: Jiang W, Macmillan $\mathrm{H}$, Madec AM and Mellins ED. Purification and characterization of GAD65-specific monoclonal autoantibodies [version 1; peer review: 1 approved, 1 approved with reservations] F1000Research 2015, 4:135 https://doi.org/10.12688/f1000research.6467.1

First published: 29 May 2015, 4:135 https://doi.org/10.12688/f1000research.6467.1 


\section{Introduction}

Type 1 diabetes (T1D) is an autoimmune disorder characterized by the immune-mediated destruction of the insulin-producing $\beta$ cells in the pancreas. Human islet cells express the $65-\mathrm{kDa}$ isoform of glutamic acid decarboxylase (GAD65), which is one of the most common autoantigens associated with the development of T1D. Anti-GAD65 autoantibodies (GAD65Abs) are detectable several years before diabetes and present in over $70 \%$ of patients at the time of diagnosis ${ }^{1}$. It has been suggested that healthy individuals also generate GAD65Abs, which are sufficiently neutralized by anti-idiotypic antibodies (anti-Id Abs), resulting in protection from GAD65-specific islet destruction ${ }^{2,3}$. Probably because the antigenbinding region of GAD65Abs is blocked by anti-Id Abs, circulating GAD65Abs in sera of healthy individuals are not detectable using GAD65-specific methods. The decline of anti-Id Abs in patients developing T1D, on the contrary, unmasks GAD65Abs, which then serve as critical serum markers in prediction and diagnostics of diabetes ${ }^{4}$. Studies of the interaction between GAD65 and recombinant GAD65Abs have suggested immunodominant epitopes on GAD65 $5^{5-9}$. However, how the recognition of these epitopes by GAD65Abs drives islet destruction, and how anti-Id Abs block GAD65Ab-mediated auto-reactivity are largely unknown. In order to generate anti-Id Abs aimed at understanding of pathophysiologic mechanism(s), and more importantly, preventing GAD65 autoreactivity, it is necessary to isolate and utilize native GAD65Abs rather than synthesizing recombinant proteins. However, no published data have ever reported on the quality of purified GAD65Abs for such aims, even though two of these human Abs (b96.11 and b78) ${ }^{10-13}$ are commercialized.

Certain limitations stem from technical issues in the purification and characterization of native GAD65Abs originated from T1D patients. The most efficient way to produce monoclonal autoantibodies in vitro is to generate monoclonal B cell lines, culture them in batches, and purify the Abs from the culture supernatant. Although many established methods have been standardized for $\mathrm{Ab}$ purification $^{14}$, the polymorphic nature of Abs and the diverse culture conditions of $\mathrm{Ab}$-secreting cell lines may impede the achievement of native autoantibody products with satisfactory quality and purity. Utilization of impure GAD65Abs in the generation of anti-Id Abs and determination of their protective role in T1D pathogenesis may lead to unconvincing or inconclusive results.

In this report, we evaluated multiple strategies for the purification of two human monoclonal GAD65Abs: DPA and DPD ${ }^{10}$. Our goal was to isolate a pure population of Abs with minimal contaminants. We also determined GAD65-binding affinity of these two autoantibodies as the initial step of molecular characterization.

\section{Materials and methods}

Reagents

Detailed information on reagents used in this study is listed in Table 1.

Table 1. Details of reagents and materials.

\begin{tabular}{|c|c|c|c|c|}
\hline Processes & Reagents and Materials & Manufacturers & Cat No. & Comments \\
\hline \multirow{6}{*}{ Cell culture } & IMDM & Life Technology & 12440061 & \multirow{4}{*}{$\begin{array}{l}\text { Complete IMDM includes } \\
10 \% \text { FBS, } 2 \mathrm{mM} \text { Glutamine, } \\
\text { and } 1 \% \text { OPI }\end{array}$} \\
\hline & Fetal Bovine Serum (FBS) & Atlanta Biologicals & S12450 & \\
\hline & L-Glutamine & Life Technology & 25030 & \\
\hline & OPI Media Supplement & Sigma & O5003-1VL & \\
\hline & AIM-V & Life Technology & 12055 & Serum-free \\
\hline & BD cell Mab Medium & BD Biosciences & 220509 & Serum-free \\
\hline RT-PCR & $\begin{array}{l}\text { SuperScript III First-Strand } \\
\text { Synthesis System }\end{array}$ & Life Technology & $18080-051$ & \\
\hline \multirow{6}{*}{ Ab purification } & GammaBind Plus Sepharose & GE Healthcare & $17-0886-01$ & \\
\hline & nProtein A Sepharose & GE Healthcare & $17-5280$ & \\
\hline & Protein L Resin & GenScript & L00239 & \\
\hline & \multirow{2}{*}{$\begin{array}{l}\text { Vivapure Ion Exchange Spin } \\
\text { Columns }\end{array}$} & Sartorius & VS-IX01QH24 & $\begin{array}{l}\text { Q Mini H Strong basic anion } \\
\text { exchanger }\end{array}$ \\
\hline & & Sartorius & VS-IX01SH24 & $\begin{array}{l}\text { S Mini H Strong acidic } \\
\text { cation exchanger }\end{array}$ \\
\hline & Superdex 200 10/300 GL & GE healthcare & $17-5175-01$ & \\
\hline \multirow[t]{2}{*}{ Gel electrophoresis } & Mini-PROTEAN TGX Precast Gel & BioRad & 456 & $\begin{array}{l}4-15 \%, 4-20 \% \text {, or } 12 \% \\
\text { polyacrylamide gel }\end{array}$ \\
\hline & 2X Laemmli Sample Buffer & BioRad & $161-0737$ & $5 \% \beta \mathrm{ME}$ freshly added \\
\hline Coomassie staining & SimplyBlue SafeStain & Life Technology & LC6065 & \\
\hline \multirow{3}{*}{ Western blotting } & Immobilon-P Membrane & EMD Millipore & IPVH 00010 & PVDF membrane \\
\hline & $\begin{array}{l}\text { Amersham ECL Western Blotting } \\
\text { Detection Reagents }\end{array}$ & GE Healthcare & RPN2106 & Reagents $\mathrm{A}$ and $\mathrm{B}$ \\
\hline & Amersham Hyperfilm ECL & GE Healthcare & 28-9068-39 & \\
\hline \multirow[t]{2}{*}{ ELISA } & $\begin{array}{l}\text { NUNC } 96 \text { Well Flat-Bottom } \\
\text { Immuno Plate, MaxiSorp, }\end{array}$ & Life Technology & 442587 & \\
\hline & TMB Substrate Reagent Set & BD Biosciences & 555214 & Reagents $A$ and $B$ \\
\hline
\end{tabular}


Cell lines

The monoclonal B cell lines secreting either DPA or DPD were immortalized by Epstein-Barr virus (EBV) transformation as described $^{10}$. These cell lines were maintained in complete Iscove's modified Dulbecco's medium (IMDM); or adapted to serum-free medium by diluting at a ratio of 1:2-1:3 every three days followed by a complete replacement after 10 days. Five million live cells were pelleted and reverse transcriptase polymerase chain reaction (RT-PCR) performed with the SuperScript III First-Strand Synthesis System (Life Technology) and antibody-specific primers (Table 2).

Autoantibody purification

The supernatants of cell cultures containing Abs were filtered through a $0.22 \mu \mathrm{m}$ membrane to remove cell debris. Abs were purified from the supernatant by affinity chromatography (as per manufacturer's instructions (Table 1)), followed by size exclusion chromatography (SEC) using a Superdex 200 gel filtration column (GE Healthcare). Fractions containing monomeric forms of each protein were pooled and analyzed by Coomassie stain or western blot.

Coomassie staining and western blotting

Purified immunoglobulin G (IgG) products were reduced in sodiumdodecyl-sulphate (SDS) -containing Laemmli sample buffer with freshly added $\beta$-mercaptoethanol ( $\beta \mathrm{ME})$ and denatured by boiling at $100^{\circ} \mathrm{C}$ for $10 \mathrm{~min}$ before separation by gel electrophoresis using Mini-PROTEAN TGX precast polyacrylamide gels (Bio-Rad). The gels were stained with SimplyBlue SafeStain (Life Technology)

Table 2. Oligonucleotides used in RT-PCR for cDNA verification.

\begin{tabular}{|c|c|c|}
\hline \multicolumn{2}{|c|}{ Specific cDNA regions } & Primer sequences \\
\hline \multicolumn{3}{|c|}{ IgG1 heavy chain } \\
\hline \multirow{6}{*}{$\mathrm{SN}^{*}$} & $\mathrm{VH} 1$ & 5'- CCCGAATTCATGGACTGGACCTGGAGG -3' \\
\hline & $\mathrm{VH} 2$ & 5'- CCCGAATTCATGGACATACTTTGTACCAC -3' \\
\hline & $\mathrm{VH} 3$ & 5'- CCCGAATTCATGGAGTTTGGGCTGAGC -3' \\
\hline & $\mathrm{VH} 4$ & 5'- CCCGAATTCATGAAACACCTGTGGTTCTT -3' \\
\hline & VH5 & 5'- CCCGAATTCATGGGGTCAACCGCCATCCT -3' \\
\hline & $\mathrm{VH} 6$ & 5'- CCCGAATTCATGTCTGTCTCCTTCCTCAT -3' \\
\hline $\mathrm{ASN}^{* *}$ & CTdomain $* \star *$ & 5'- CTAGGCCCCCTGTCCGATCAT -3' \\
\hline \multicolumn{3}{|c|}{$\kappa$ light chain } \\
\hline \multirow{5}{*}{ SN } & $V_{\kappa} 1$ & 5'- CACAAGCCCAGCAACACCAAGGTGGAC -3' \\
\hline & Vк2 & 5'- GGGGGGAAGAGGAAGACTGACGGTCC 3' \\
\hline & $\mathrm{V} \kappa 3$ & 5'- GGGTGTACACCTGTGGTTCTCGGGGCTG 3' \\
\hline & $V_{\kappa} 4$ & 5'- GCAGGTGTAGGTCTGGGTGCC -3' \\
\hline & Vк5 & 5'- TGGCGGGAAGATGAAGACAG -3' \\
\hline ASN & $\mathrm{C \kappa}$ & 5'- CTAAGACTCTCCCCTGTTGAA -3' \\
\hline \multicolumn{3}{|c|}{$\lambda$ light chain } \\
\hline \multirow{6}{*}{ SN } & $\mathrm{V} \lambda 1$ & 5'- CCCGAATTCATGGCCTGGGCTCCACTACT -3' \\
\hline & $\mathrm{V} \lambda 2$ & 5'- CCCGAATTCATGGCATGGATCCCTCTCTT -3' \\
\hline & $\mathrm{V} \lambda 3$ & 5'- CCCGAATTCATGGCCTGGGCTCTGCTGCTC -3' \\
\hline & $\mathrm{V} \lambda 4$ & 5'- ACCTATAAATATTCCGGATTATTCA -3' \\
\hline & $\mathrm{V} \lambda 5$ & 5'- TCTTGCCGGGTCCCAGG -3' \\
\hline & $\mathrm{V} \lambda 6$ & 5'- GGTCTCCAACAAAGCCCTCCC -3' \\
\hline ASN & $C \lambda$ & 5'- TTATGAACATTCTGTAGGGGCCACT -3' \\
\hline
\end{tabular}


and destained with Milli-Q water for at least $1 \mathrm{~h}$ before imaging of $\mathrm{IgG}$ heavy and light chains. To differentiate the heavy and light chains of human IgG from non-specific contaminants co-purified from cell culture supernatant, proteins on the gel were transferred to Immobilon-P membrane (EMD Millipore) for human IgG detection. Goat F(ab')2 anti-human Ig $(2.5 \mathrm{mg} / \mathrm{ml}$, Life Technology, Inc; used at 1:3000 dilution) followed by HRP-donkey anti-goat $\mathrm{IgG}(0.4 \mathrm{mg} / \mathrm{ml}$, Santa Cruz Biotechnology, Inc; used at 1:10000 dilution) (see Table 3 for full $\mathrm{Ab}$ information) were used to detect human Ig.

\section{Enzyme-linked immunosorbent assay (ELISA) for affinity} measurement

Recombinant GAD65 (a gift from Peter van Endert, Institut National de la Santé et de la Recherche Médicale, France) in 20 mM 4-(2hydroxyethyl)-1-piperazineethanesulfonic acid (HEPES)+1 $\mathrm{mM}$ pyridoxal phosphate (PLP)+50\% Glycerol, $\mathrm{pH} 7.4$, was stored in aliquots at $-80^{\circ} \mathrm{C}$; and the reactivity was verified by ELISA using commercially available mouse anti-GAD65 IgG1 and horseradish peroxidase (HRP) labeled goat anti-mouse IgG1 (Table 3). The ELISA protocol for GAD65/autoantibody interaction has been described (see Table 4).

\section{Results}

Both GAD65Abs purified in this study belong to the human IgG1 $\left(\gamma_{1}\right)$ subclass; DPA uses a $\lambda$ light chain and DPD uses a $\kappa$ light chain ${ }^{10}$. Prior to the purification of soluble DPA or DPD IgG from cell culture supernatant, we first validated Ig cDNA expression in each cell line using standard RT-PCR (Figure 1). Note that we used an antisense oligonucleotide to prime the 3'-end of membrane IgG heavy chain cytoplasmic domain instead of one priming the 3'-end of the

Table 3. Abs generated or used in this report.

\begin{tabular}{|c|c|c|c|c|}
\hline Antibodies & Manufacturers & Cat No. & RRID & Concentrations \\
\hline DPA & \multicolumn{4}{|c|}{ IgG1 (VH4-DH-JH2)/ $\lambda(\mathrm{V} \lambda 3-J L 2)$, purified in this study } \\
\hline DPD & \multicolumn{4}{|c|}{ IgG1 (VH4-DH-JH4)/א(Vк4-Jk4), purified in this study } \\
\hline $\begin{array}{l}\text { Goat } F(a b ') 2 \text { anti- } \\
\text { human Ig }\end{array}$ & Life Technology & H17000 & RRID:AB_1500566 & $\begin{array}{l}1: 3000 \text { for western } \\
\text { blotting }\end{array}$ \\
\hline $\begin{array}{l}\text { HRP- Donkey anti- } \\
\text { goat IgG }\end{array}$ & $\begin{array}{l}\text { Santa Cruz } \\
\text { Biotechnology, Inc. }\end{array}$ & sc-2020 & RRID:AB_631728 & $\begin{array}{l}\text { 1:10000 for western } \\
\text { blotting }\end{array}$ \\
\hline $\begin{array}{l}\text { HRP-Goat F(ab')2 } \\
\text { anti-human Ig } \\
\text { polyvalent }\end{array}$ & Life Technology & $\mathrm{H} 17107$ & Discontinued & $\begin{array}{l}\text { 1:3000 for western } \\
\text { blotting } \\
1: 20000 \text { for ELISA }\end{array}$ \\
\hline $\begin{array}{l}\text { Mouse anti-GAD65 } \\
\text { mAb, IgG1 isotype }\end{array}$ & Sigma & SAB4200232 & RRID:AB_10762670 & $1: 2000$ for ELISA \\
\hline $\begin{array}{l}\text { HRP-goat anti-mouse } \\
\text { IgG1 }(\gamma 1)\end{array}$ & Life Technology & A10551 & RRID:AB_10561701 & 1:2500 for ELISA \\
\hline
\end{tabular}

Table 4. ELISA protocol.

\begin{tabular}{|c|c|c|c|}
\hline Steps & Reagents & Volumes & Conditions \\
\hline \multirow[t]{2}{*}{ Antigen Coating } & $\begin{array}{l}\text { GAD65 in } 100 \mathrm{mM} \\
\text { Carbonate-Bicarbonate } \\
\text { Buffer pH } 9.5\end{array}$ & $100 \mu \mathrm{l} /$ well & $4^{\circ} \mathrm{C}$ overnight \\
\hline & PBS + 0.05\% Tween 20 & $300 \mu \mathrm{l} / \mathrm{well}$ & Wash 3 times \\
\hline \multirow{2}{*}{ Blocking } & $\mathrm{PBS}+2 \% \mathrm{BSA}$ & $250 \mu \mathrm{l} / \mathrm{well}$ & Room temperature (RT), $1 \mathrm{~h}$ \\
\hline & PBS + 0.05\% Tween 20 & $300 \mu \mathrm{l} /$ well & Wash 3 times \\
\hline \multirow{2}{*}{ Antibody Binding } & $\mathrm{Ab}$ in $\mathrm{PBS}+1 \% \mathrm{BSA}$ & $100 \mu \mathrm{l} /$ well & $37^{\circ} \mathrm{C}, 2 \mathrm{~h}$ \\
\hline & PBS + 0.05\% Tween 20 & $300 \mu \mathrm{l} / \mathrm{well}$ & Wash 5 times \\
\hline \multirow{2}{*}{ Secondary Antibody Binding } & $\begin{array}{l}\text { HRP-Goat anti-hlg's in } \\
\text { PBS }+1 \% \text { BSA }\end{array}$ & $100 \mu \mathrm{l} /$ well & $\mathrm{RT}, 1 \mathrm{~h}$ \\
\hline & PBS + 0.05\% Tween 20 & $300 \mu \mathrm{l} /$ well & Wash 7 times \\
\hline \multirow{2}{*}{ Detecting } & TMB substrate $A$ and $B$ & $100 \mu \mathrm{l} /$ well & $\mathrm{RT}, 30 \mathrm{~min}$ \\
\hline & $1 \mathrm{M}$ Sulfuric acid & $50 \mu \mathrm{l} /$ well & Measure absorbance directly \\
\hline
\end{tabular}




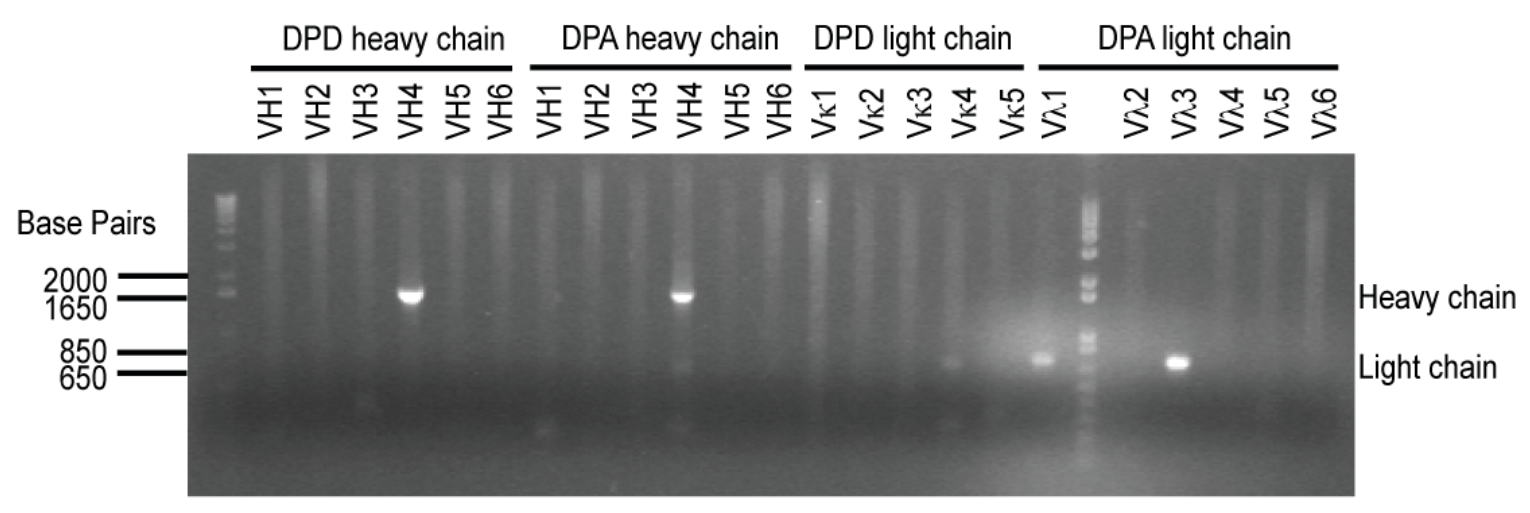

Figure 1. Ig cDNAs in monoclonal GAD65Ab-secreting cell lines. The RT-PCR amplified heavy chain cDNA using the indicated 5' primer and the 3' cytoplasmic-tail-specific primer, or the amplified light chain cDNA using the indicated 5' primer and the 3' constant-region-specific primer, are shown. Note that the PCR product amplified by V $\lambda 1$ from DPA-secreting cell line provided the same sequence as the one amplified by $\mathrm{V} \lambda 3$, indicating that $\mathrm{V} \lambda 1$ may result in non-specific primer annealing and PCR amplification.

IgG heavy chain constant region used elsewhere, in order to generate the entire sequence of the heavy chain (Supplementary file S1).

Although both anti-GAD65 Ab-secreting cell lines are derived from peripheral blood mononuclear cells (PBMCs) of a T1D patient ${ }^{10}$, their culture conditions are significantly different. The DPA cell line expanded well in both serum-supplemented and serum-free medium, while the DPD cell line survived only in serum-supplemented medium. Fetal bovine serum (FBS) is widely used in tissue-culture medium to provide essential proteins, nutrients and other uncharacterized factors for optimum cell growth; however, the presence of bovine $\operatorname{IgG}(\mathrm{bIgG})$ in the serum (up to $50 \mathrm{mg} / \mathrm{L}$ ) is the main source of contamination in human $\mathrm{IgG}(\mathrm{hIgG})$ purification. Bovine serum albumin (BSA) is also commonly used at a high concentration in culture medium (can be over $1 \mathrm{mg} / \mathrm{ml}$ ), and binds non-specifically during the protein purification process.

Affinity purification using antigens or IgG-binding proteins (e.g., Protein A, G and L) is very effective for Ab production, with antigen affinity purification being the most specific technique and providing the purest batches of antibody. However, GAD65Ab purification using recombinant GAD65 (rGAD65) for antigen-specific affinity purification is difficult because rGAD65 is unstable and requires pyridoxal phosphate (PLP) for stabilization. Considering the inevitable exposure of rGAD65 pre-coupled to resin to the extreme $\mathrm{pH}$ $(<4$ or $>10)$ in elution and regeneration steps, this would not be a viable option. We therefore chose IgG-binding proteins in our attempt to affinity purify GAD65Abs without potential protein contaminants. Both Protein A and $\mathrm{G}$ recognize the Fc domain of IgG from human and bovine sera, while protein $\mathrm{L}$ binds to $\kappa$ light chain. Gammabind sepharose beads (GE healthcare) use a recombinant form of Protein G (rProtein G), which significantly reduces the nonspecific binding of BSA to the resin. Purification of IgG from the supernatant of DPA cell culture (grown in FBS-containing medium) on $\mathrm{rProtein} \mathrm{G}$ resin resulted in purer IgG (Figure 2A), than using native Protein A resin (nProtein A) (Figure 2B). However, the purified IgG products from both rProtein $\mathrm{G}$ and nProtein A still contained a high molecular-weight (MW; MW>100 kDa) component besides the anticipated heavy chain $(\sim 50 \mathrm{kDa})$ and light chain $(25 \mathrm{kDa})$ on coomassie-stained protein gels. Western blotting analysis suggested that this component did not belong to human Ig (Figure 2C). The relative percentage of contamination with the high MW protein in IgG purified using nProtein A was significantly lower than when purified with rProtein G (Figure 2A, Figure 2B). This component may reflect bIgG-associated contaminants, as bIgG has lower binding affinity for nProtein A than rProtein G. To test this, we gradually adapted DPA cells from FBScontaining medium to FBS-free medium and were able to affinitypurify hIgG from the culture supernatant without bIgG using rProtein G (Figure 2D). We further separated DPA hIgG from any BSA contamination by SEC. The comparison between DPA purified using different methods and bIgG purified from pure FBS confirmed that the high MW contaminate is associated with bIgG (Figure 2D and Figure 3). Importantly, we demonstrated that serumfree culture is key to isolating highly pure DPA hIgG.

In contrast, DPD did not grow well in the serum-free medium we tested, and thus we opted to use Protein $\mathrm{L}$ as an alternative method to obtain more pure hIgG from this line. Protein L binds the light chain of IgG and DPD has a $\kappa$ light chain. Notably, no previous evidence suggested that Protein L distinguishes $\kappa$ chain of hIgG from $\mathrm{bIgG}$; however, we found that Protein L affinity purification followed by SEC separation generated DPD hIgG with satisfactory purity and no detectable bIgG or bIgG-associated high MW proteins even though DPD cell culture contains 10\% FBS (Figure 2E). We also demonstrated that ion-exchange chromatography is not appropriate to separate $\mathrm{hIgG}$ from $\mathrm{bIgG}$, as the high MW bIgG-associated 
A

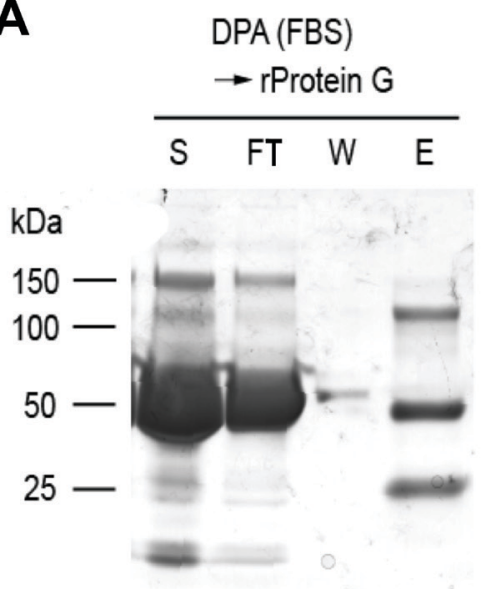

B

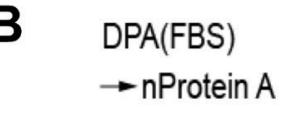

Non-specific

BSA

Heavy chain

Light chain

D

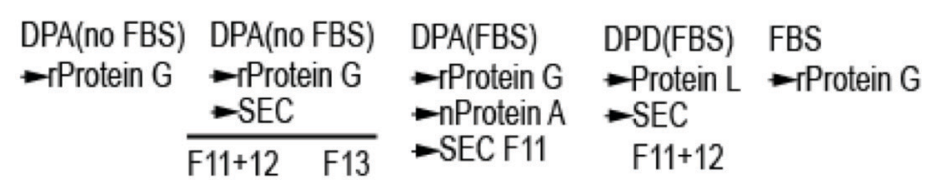

E
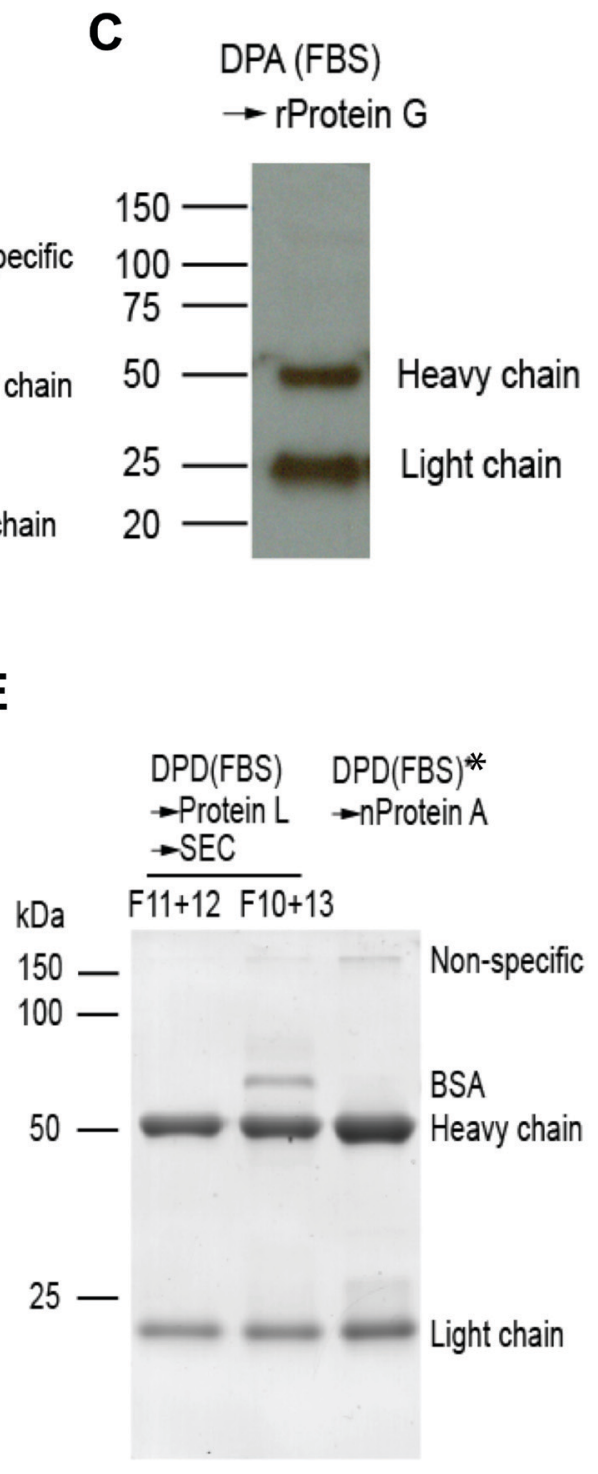

Figure 2. GAD65Abs purified using different methods. (A, B) GAD65Ab-secreting cell lines were cultured with or without FBS, as indicated in parentheses, and the culture supernatant was applied to a pre-packed column containing one of the IgG-binding resins (right-pointing arrows) for affinity purification. Shown are Coomassie-stained gel images. S: supernatant; FT: flow through; W: wash; E: eluate. (C) Western blotting analysis of eluted proteins from (A) using anti-human Ig antibodies. (D, E) Eluate from (A) and (B) was applied to a second column containing another IgG-binding resin or applied to a gel filtration column for size exclusion chromatography (SEC). Fractions (F) eluted from the gel filtration column were pooled before analysis by gel electrophoresis and Coomassie staining. Pure FBS was also applied to the gammabind resin-containing column for purification of bovine IgG. DPD (FBS*) indicates DPD culture supernatant pre-depleted with gammabind sepharose (Original gel images in Supplementary materials S2). 


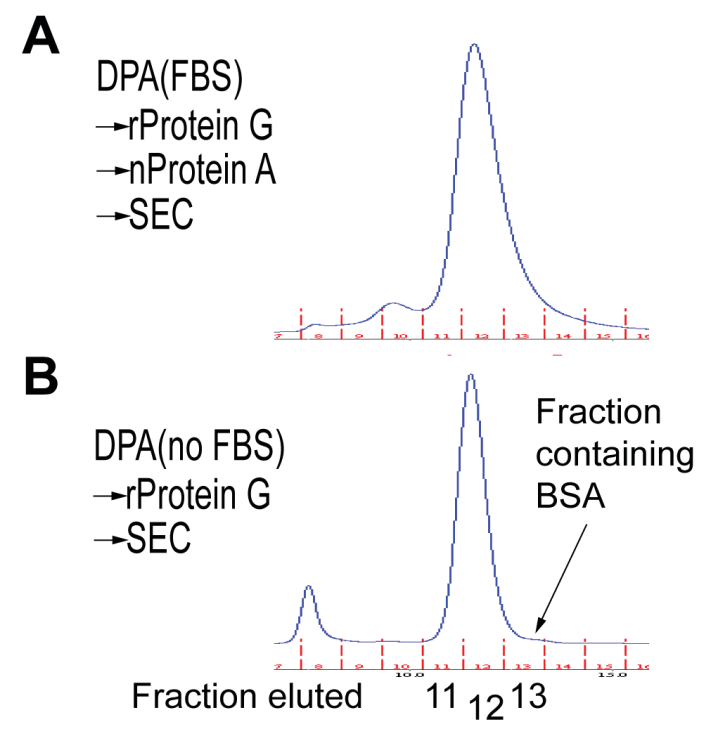

Figure 3. SEC profile of DPA with (A) or without (B) bovine IgG or BSA contaminants. (A) DPA with bovine IgG eluted in more fractions $(10-13 \mathrm{ml}, 1 \mathrm{ml}$ per fraction), likely containing blgG, unidentified blgG-associated proteins, and BSA. (B) Pure DPA without blgG mainly eluted at two fractions ( 11 and $12 \mathrm{ml}$ ), which can be easily separated from BSA ( 66.5 kDa, fraction 13) based on the difference in their sizes.

protein(s) were present in all fractions eluted from anion or cation exchange columns (Figure 4).

We then determined the binding affinity of the purified DPA and DPD to rGAD65 by ELISA (Figure 5). Given the instability of rGAD65, the measurement of its concentration was inaccurate. To overcome this problem, we coated the ELISA plate with two concentrations of rGAD65 $(10-100 \mathrm{nM})$ differing by 3-fold and incubated immobilized rGAD65 with titrated amounts of purified DPA or DPD monoclonal Abs at $37^{\circ} \mathrm{C}$ for $2 \mathrm{~h}$. The concentration of immobilized rGAD65 did not influence the calculation of the dissociation constant $\left(K_{D}\right)$. We assumed that the duration of incubation was sufficient for the interaction between rGAD65 and GAD65Ab to reach equilibrium and fitted the data to a single site binding equation:

$$
y=B_{\max } * x /\left(K_{D}+x\right)
$$

to estimate $K_{D}$ (Table 5). Purified DPA has over 100-fold higher rGAD65-binding affinity (the inverse of $K_{D}$ ) than purified DPD.

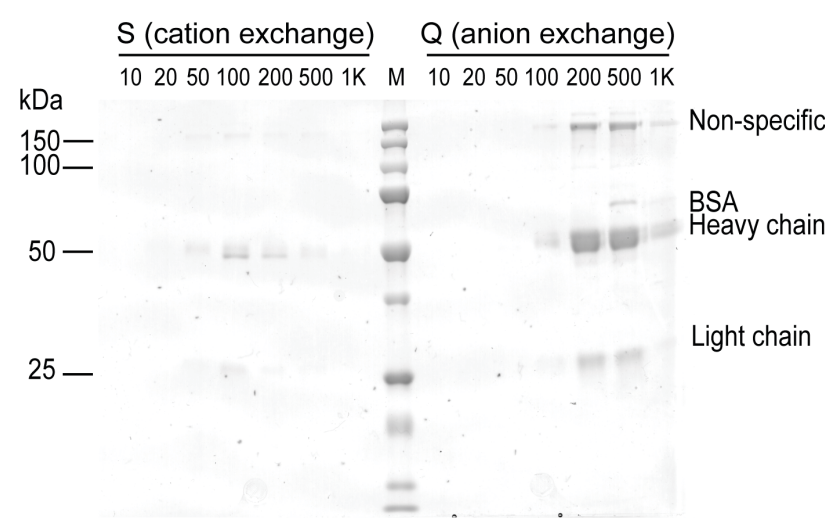

Figure 4. Ion exchange chromatography (IEC) of IgG purified from the DPA-secreting $B$ cell line. Neither cation nor anion exchange separated hlgG from blgG, as the non-specific blgG associated band on the protein gel was present in all eluted fractions that contained IgG.

\section{Conclusions}

To the best of our knowledge, purification and characterization of native GAD65Ab, free from culture medium-derived contaminants such as bIgG and BSA, have not been reported previously, in spite of the availability of monoclonal cell lines secreting these $\mathrm{Abs}^{10,11}$. Our goal was to obtain a very pure preparation of GAD65-specific hIgG. Here, we demonstrate several strategies to overcome limitations associated with affinity purification that would be applicable to the purification of many other antibodies: (1) antigen-specific affinity purification is always superior, if the autoantigen itself can be easily produced and can tolerate exposure to $\mathrm{pH}$ extremes; (2) when dealing with an unstable autoantigen (most often), the attempt to adapt cells to serum-free medium is worthwhile to avoid bIgG contamination; (3) Protein L recognizes the light chains of Ig from different species, however, as we have shown here Protein $\mathrm{L}$ may preferentially bind human rather than bovine $\kappa$ chain and provide an alternative approach to purification of autoreactive $\mathrm{hIgG}(\kappa)$.

It is of interest that there is over 100-fold difference in the rGAD65binding affinity between DPA and DPD. Without understanding the mechanism, it is hard to predict the relationship between autoantigen binding affinity and the severity of disease. However, this finding reminds us that low affinity autoantibodies indeed exist, but are less likely to be detected in diagnostic tests, considering the binding of GAD65Abs by anti-Id Abs. Therefore, the detection threshold in diagnostic tests for measuring GAD65Abs or other autoantibodies in patient sera may need further optimization for a more thorough monitoring of low affinity autoantibodies and prediction of T1D. 
A

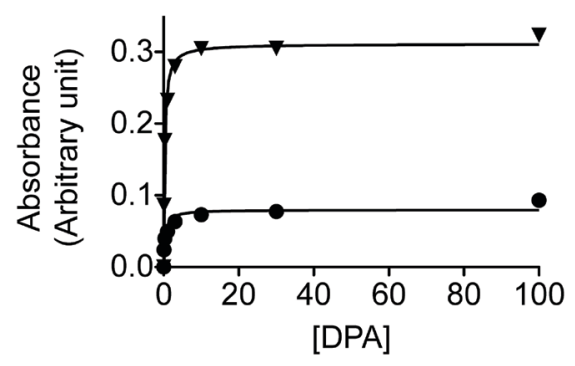

B

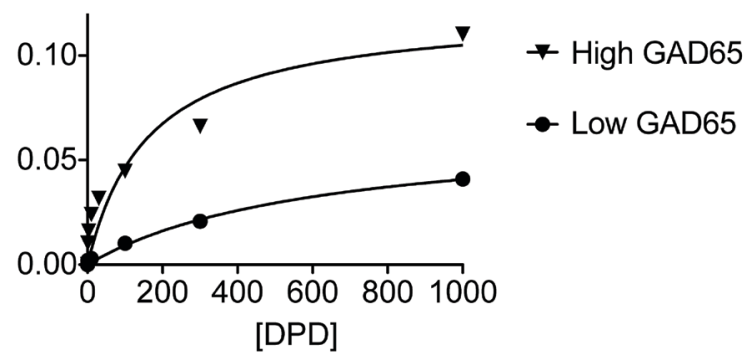

Figure 5. Binding of purified GAD65Abs to recombinant GAD65. 96-well plates were coated with two different concentrations of rGAD65 before incubation with different concentrations of (A) DPA and (B) DPD autoantibodies. The amount of GAD65Ab/rGAD65 complexes at equilibrium were measured by ELISA and plotted against the concentration of GAD65Abs. Data were fit to a single site binding equation for calculation of the dissociation constant.

\section{Table 5. Fitting parameters and the dissociation constant.}

\begin{tabular}{|c|c|c|c|c|}
\hline \multirow[b]{2}{*}{ mAb } & \multirow[b]{2}{*}{ Antigen } & \multirow[b]{2}{*}{$B_{\text {max }}$ (Arbitrary unit) } & \multicolumn{2}{|l|}{$K_{D}(\mathrm{nM})$} \\
\hline & & & Fitted value & $\begin{array}{l}\text { Estimated order of } \\
\text { magnitude }\end{array}$ \\
\hline \multirow{2}{*}{ DPA } & Low GAD65 & $0.07982 \pm 0.004650$ & $0.3836 \pm 0.1262$ & \multirow{2}{*}{$<1$} \\
\hline & High GAD65 & $0.3111 \pm 0.005079$ & $0.2624 \pm 0.02543$ & \\
\hline \multirow{2}{*}{ DPD } & Low GAD65 & $0.6537 \pm 0.007078$ & $606.7 \pm 136.8$ & \multirow{2}{*}{$>100$} \\
\hline & High GAD65 & $0.1155 \pm 0.01786$ & $136.2 \pm 67.33$ & \\
\hline
\end{tabular}

\section{Author contributions}

WJ and EDM conceived the study. WJ designed the experiment, carried out the research and prepared the first draft of the manuscript. HM contributed to the design of experiments and provided expertise in cell culture. AM provided the DPA and DPD cell lines. All authors were involved in the preparation and revision of the draft manuscript and have agreed to the final content.

\section{Competing interests}

No competing interests were disclosed.

\section{Grant information}

This work was supported by National Institutes of Health Grants AI095813 and AI075253 (both to E.D.M.), the Stanford NIH/NCRR
CTSA award UL1 RR025744 (to W.J.), National Institutes of Health/National Center for Research Resources Clinical and Translational Science Award UL1 RR025744 (to H.M.), and the Lucile Packard Foundation for Children's Health. H.M. was also supported by National Institutes of Health Training Grant T32 AI07290 to the Stanford Interdisciplinary Program in Immunology.

I confirm that the funders had no role in study design, data collection and analysis, decision to publish, or preparation of the manuscript.

Acknowledgments

We thank Peter van Endert (Institut National de la Santé et de la Recherche Médicale, France) for providing the recombinant GAD65 protein and Taejin Yoon (former member of the Mellins laboratory) for providing advice and expertise in protein purification.

\section{Supplementary Materials}

Supplementary file S1.

Sequences for human IgG DPA and DPD

Click here to access the data.

Supplementary materials S2.

Original gel images for Figure 2

Click here to access the data. 
1. Taplin CE, Barker JM: Autoantibodies in type 1 diabetes. Autoimmunity. 2008; 41(1): 11-18.

PubMed Abstract | Publisher Full Text

2. Oak S, Gilliam LK, Landin-Olsson M, et al.: The lack of anti-idiotypic antibodies, not the presence of the corresponding autoantibodies to glutamate decarboxylase, defines type 1 diabetes. Proc Natl Acad Sci U S A. 2008; 105(14): 5471-5476. PubMed Abstract | Publisher Full Text | Free Full Text

3. Wang $X$, Zhang A, Liu Y, et al:: Anti-idiotypic antibody specific to GAD65 autoantibody prevents type 1 diabetes in the NOD mouse. PLOS One. 2012; 7(2): e32515.

PubMed Abstract | Publisher Full Text | Free Full Text

4. Larsson HE, Jönsson I, Lernmark A, et al:: Decline in titers of anti-idiotypic antibodies specific to autoantibodies to GAD65 (GAD65Ab) precedes development of GAD65Ab and type 1 diabetes. PLOS One. 2013; 8(6): e65173.

PubMed Abstract | Publisher Full Text | Free Full Text

5. Richter W, Shi Y, Baekkeskov S: Autoreactive epitopes defined by diabetesassociated human monoclonal antibodies are localized in the middle and C-terminal domains of the smaller form of glutamate decarboxylase. Proc Natl Acad Sci U S A. 1993; 90(7): 2832-2836.

PubMed Abstract | Publisher Full Text | Free Full Text

6. Powers AC, Bavik K, Tremble J, et al:: Comparative analysis of epitope recognition of glutamic acid decarboxylase (GAD) by autoantibodies from different autoimmune disorders. Clin Exp Immunol. 1999; 118(3): 349-356. PubMed Abstract | Publisher Full Text | Free Full Text

7. Schwartz HL, Chandonia JM, Kash SF, et al:: High-resolution autoreactive epitope mapping and structural modeling of the $65 \mathrm{kDa}$ form of human glutamic acid decarboxylase. J Mol Biol. 1999; 287(5): 983-999. PubMed Abstract | Publisher Full Text
8. Fenalti G, Hampe CS, O'connor K, et al: Molecular characterization of a disease associated conformational epitope on GAD65 recognised by a human monoclonal antibody b96.11. Mol Immunol. 2007; 44(6): 1178-1189. PubMed Abstract | Publisher Full Text

9. Fenalti G, Hampe CS, Arafat $Y$, et al:: $\mathbf{C O O H}$-terminal clustering of autoantibody and T-cell determinants on the structure of GAD65 provide insights into the molecular basis of autoreactivity. Diabetes. 2008; 57(5): 1293-1301. PubMed Abstract | Publisher Full Text

10. Madec AM, Rousset F, Ho S, et al.: Four IgG anti-islet human monoclonal antibodies isolated from a type 1 diabetes patient recognize distinct epitopes of glutamic acid decarboxylase 65 and are somatically mutated. J Immunol. 1996; 156(9): 3541-3549. PubMed Abstract

11. Tremble J, Morgenthaler NG, Vlug A, et al.: Human B cells secreting immunoglobulin $G$ to glutamic acid decarboxylase- 65 from a nondiabetic patient with multiple autoantibodies and Graves' disease: a comparison with those present in type 1 diabetes. J Clin Endocrinol Metab. 1997; 82(8): 2664-2670. PubMed Abstract | Publisher Full Text

12. Jury $\mathrm{K}$, Sohnlein $\mathrm{P}$, Vogel $\mathrm{M}$, et al:: Isolation and functional characterization of recombinant GAD65 autoantibodies derived by IgG repertoire cloning from patients with type 1 diabetes. Diabetes. 2001; 50(9): 1976-1982. PubMed Abstract | Publisher Full Text

13. Padoa CJ, Banga JP, Madec AM, et al.: Recombinant Fabs of human monoclonal antibodies specific to the middle epitope of GAD65 inhibit type 1 diabetes-specific GAD65Abs. Diabetes. 2003; 52(11): 2689-2695. PubMed Abstract | Publisher Full Text

14. Committee on Methods of Producing Monoclonal Antibodies, I. f. L. A. R., National Research Council. Monoclonal Antibody Production. National Academy Press. 1999 Reference Source 


\section{Open Peer Review}

\section{Current Peer Review Status:}

\section{Version 1}

Reviewer Report 10 March 2016

https://doi.org/10.5256/f1000research.6939.r9336

(C) $2016 \mathrm{He} \mathbf{X}$. This is an open access peer review report distributed under the terms of the Creative Commons Attribution License, which permits unrestricted use, distribution, and reproduction in any medium, provided the original work is properly cited.

\section{Xiao He}

Department of Pathology, University of Utah, Salt Lake City, UT, USA

This is a good Ab validation study, where the authors testified multiple established Ab purification strategies in an autoimmune disease model. Non-specific proteins present in an autoantibody product could potentially affect its usage in many aspects. For example, the authors pointed out that pure autoantibodies can be more efficient in the study of both autoantigens and anti-idiotypic antibodies, although neither were further characterized. As this article mainly validated and discussed purification strategies, it will be more straightforward to emphasize only on $A b$ production, but not characterization, which was not the focus as I can tell.

Competing Interests: No competing interests were disclosed.

\section{I confirm that I have read this submission and believe that I have an appropriate level of expertise to confirm that it is of an acceptable scientific standard.}

Author Response ( ) 22 Apr 2016

Wei Jiang, Stanford University, Stanford, USA

In light of Dr. He's comment we have edited the title to "Optimized purification strategies for the elimination of non-specific products in the isolation of GAD65-specific monoclonal autoantibodies" in order to emphasize purification rather than characterization of the GAD65-specific antibodies. The abstract and introduction was also updated to reflect the focus on purification.

\section{Competing Interests: no}


(C) 2015 Soll D. This is an open access peer review report distributed under the terms of the Creative Commons Attribution License, which permits unrestricted use, distribution, and reproduction in any medium, provided the original work is properly cited.

\section{David Soll}

Department of Biology, University of Iowa, Iowa City, IA, USA

This article describes simple purification methods of highly pure antibodies from supernatant of human monoclonal B-cell cultures. However, all of the methods are already known. They are not new. One good thing that this article is showing is an example for the purification grades depending on the purification methods and culturing condition of the cells with and without FCS to avoid contamination with bovine antibodies. In my opinion, the abstract is not appropriated and overemphasized with points that are not directly related to this article.

Characterization of the antibodies is weak.

For the sentence on page 2 at the end of second paragraph "Utilization of impure GAD65Abs in the generation of anti-Id Abs and determination of their protective role in T1D pathogenesis may lead to unconvincing or inconclusive results.", the authors have to explain with citations, why the purity of the antibody is important, and how the impure antibodies lead to unconvincing or inconclusive results.

Competing Interests: No competing interests were disclosed.

\section{I confirm that I have read this submission and believe that I have an appropriate level of expertise to confirm that it is of an acceptable scientific standard, however I have significant reservations, as outlined above.}

Author Response ( ) 22 Apr 2016

Wei Jiang, Stanford University, Stanford, USA

Per Dr. Soll's comment we have edited the title to "Optimized purification strategies for the elimination of non-specific products in the isolation of GAD65-specific monoclonal autoantibodies" to show that we have utilized known methods but we very specifically optimized the purification of the GAD65-specific antibodies.

The abstract and introduction was updated to focus on our goal of optimization and validation of approaches for the purification of highly pure autoantibodies. These approaches are not novel, but the specific application to purification of anti-GAD65 antibodies were never evaluated.

We agree that the characterization is weak and have updated the abstract and introduction to focus on purification. Highly purified autoantigen-specific antibodies could be suitable for the downstream study of mechanisms underlying the interaction between autoantigen and antibody or autoantibody and anti-idiotypic antibody which is beyond the scope of this current report.

We have removed the sentence on page 2 that read "Utilization of impure GAD65Abs in the 
generation of anti-Id Abs and determination of their protective role in T1D pathogenesis may lead to unconvincing or inconclusive results." The purity of autoantibody might be important, for example, in the generation of anti-Id Abs; otherwise, there might be antibyproduct Abs in the final mixture, which can be problematic. Since there are currently no publications reporting an issue caused by non-specific by-products in the production of antiGAD65 autoantibodies we have removed the sentence.

Competing Interests: No

The benefits of publishing with F1000Research:

- Your article is published within days, with no editorial bias

- You can publish traditional articles, null/negative results, case reports, data notes and more

- The peer review process is transparent and collaborative

- Your article is indexed in PubMed after passing peer review

- Dedicated customer support at every stage

For pre-submission enquiries, contact research@f1000.com 